\title{
Jogo de tabuleiro USPontos: experimentos visuais na lida com problemas de sinalização, localização e circulação na Cidade Uni- versitária
}

The board game "USPontos": visual experiments in the handling with signaling, localization and circulation problems in the University City

NORMANDI, Diego | diegonmd@usp.br

DEL REY, Alexandre | alexandrep.delrey@gmail.com

ZAMBRA, Christian | christian.zambra@gmail.com

LEAL, Dalila | dalila.leal@usp.br

\section{Resumo}

Este artigo relata experimento realizado junto ao Programa de Pós-Graduação em Design da Universidade de São Paulo, na disciplina "Design Visual: processos experimentais". Consiste no detaIhamento do conjunto de problematizações, etapas, procedimentos e soluções que conduziram a criação do jogo de tabuleiro "USPontos: um passeio na Cidade Universitária", entendido como ferramenta didática para compreensão da circulação de pedestres e passageiros das linhas 8012 e 8022 no campus da capital, bem como, do ponto de vista projetual, uma jornada nas diferentes áreas de atuação e linguagem do Design Visual.

Palavras Chave: Jogo, Design Visual, Mobilidade, Ludicidade, Jornada do usuário

\begin{abstract}
This article reports an experiment realized in the Graduate Program in Design of the University of São Paulo, in the discipline "Visual Design: experimental processes". It consists of detailing the set of questions, steps, procedures and solutions that led to the creation of the board game "USPontos: a walk in the university city", understood as a didactic tool to understand the movement of pedestrians and passengers of lines 8012 and 8022 on campus of the capital, as well as, from the design point of view, a journey in the different areas of Visual Design's performance and language.
\end{abstract}

Keywords: Game, Visual Design, Mobility, Ludicity, User Journey 


\section{Introdução}

A mobilidade urbana é um dos principais desafios do século XXI. Algumas das maiores cidades do planeta convivem com graves problemas decorrentes desta questão, dentre eles: congestionamentos, baixa qualidade do transporte público, longas distâncias a serem percorridas e grande perda de tempo em deslocamentos. (Rodrigues, J. S., 2014). Dados da pesquisa de Mobilidade Urbana da Região Metropolitana de São Paulo ${ }^{1}$ apontam que os trajetos em ônibus representam $82 \%$ das viagens municipais e intermunicipais realizadas diariamente na metrópole paulista. Abordagem amplamente discutida atualmente é a que leva em consideração a satisfação do usuário do transporte público. Para Birnerová (2007), a satisfação dos usuários deve se tornar o principal objetivo das empresas de transporte público no processo de decisão sobre a gama de serviços a serem oferecidos. No Brasil, a tendência deve ser acompanhada.

A Universidade de São Paulo é uma das maiores da América Latina, e seu principal campus, o do Butantã, também conhecido como "Cidade Universitária", situado na capital paulista, agrega grande parte dos cursos de Graduação, Pós-Graduação, unidades acadêmicas, espaços de recreação, cultura e esporte da Universidade, o que, por sua vez, faz com que a sede conte com grande área territorial. São aproximadamente 7.920 .000 metros quadrados, com malha viária de 60 quilômetros e fluxo diário entre 80.000 e 100 mil pessoas, entre comunidade acadêmica e comunidade externa. A mobilidade neste campus ocorre à pé, bicicleta, automóveis e ônibus, dos quais, a depender do trajeto, a melhor ou mais rápida opção não pode ser definida com exatidão. Para atender aos 54 pontos de ônibus distribuídos no campus, 9 linhas circulam nas vias, às quais apenas 2,6km são destinados ao uso exclusivo desta modalidade de transporte público. Para os ciclistas, a mesma quantidade territorial de ciclofaixas está disponível. Ao passo que há $130 \mathrm{~km}$ de calçadas para atender aos pedestres².

Ritter e Webber (1973) conceituaram o que consideram wicked problems, donde podemos incluir a mobilidade urbana como processo inserido neste conceito. Da mesma forma, o transporte público dentro da Universidade de São Paulo parece ter contornos da mesma espécie, já que muitos dos que estão envoltos ao serviço (a comunidade acadêmica, o poder público, os que circulam no espaço, entre outros) e o deslocamento dentro e fora do campus dependem de uma série de decisões que impactam stakeholders com interesses específicos (às vezes até conflitantes).

Neste trabalho, optamos por abordagem experimental na utilização do Design para a compreensão e, quem sabe, a solução de problema complexo: a mobilidade dentro da Cidade Universitária da USP por meio das linhas de ônibus 8012 e 8022 e/ou à pé. Abraçando ampla temática como a Mobilidade Urbana dentro da Cidade Universitária, não nos orientamos a solucionar um problema, uma vez que a definição de wicked problem somada ao tempo disponível para realização do trabaIho e aos objetivos do grupo de pesquisadores, apontou para a problematização da questão e sua compreensão. Após mergulho na problemática de pesquisa, partimos para uma segunda fase, na qual optamos por desenvolver um produto que fosse capaz de prototipar um modelo do desafio da

\footnotetext{
1 Pesquisa realizada em 2012 e divulgada em março de 2014. A pesquisa é feita de dez em dez anos em conjunto pelo Metrô, pela Companhia Paulista de Trens Metropolitanos (CPTM), pela Empresa Metropolitana de Transportes Urbanos de São Paulo (EMTU), São Paulo Transportes S. A. (SPTrans) e pela Companhia de Engenharia de Tráfego (CET). Tem por objetivo atualizar informações sobre viagens diárias dos moradores da Região Metropolitana de São Paulo, servindo de base para os estudos de planejamento em transportes.

${ }^{2}$ Todos os dados relacionados aos números da Cidade Universitária foram coletados do relatório disponibilizado pela Prefeitura da USP da Capital. Disponível em: <http://www.puspc.usp.br/wp-content/uploads/sites/159/2017/07/Dados-Gerais-do-Campus-2017.xlsx-Plan1-1.pdf>. Acesso em: 26 de março de 2018.
} 
mobilidade, o que resultou em um jogo de tabuleiro: o USPontos.

\section{Contextualização / Problema de Pesquisa}

O Design é apontado como uma das áreas onde se encontram os métodos e processos capazes de "resolver" problemas difíceis, os chamados wicked problems. (Ritter; Weber, 1973; Buchanan, 1992). Conforme Rittel e Weber (1973), os wicked problems compõem uma espécie de classe de problemas dos sistemas sociais, que se diferenciam de problemas das áreas exatas, nas quais os problemas se encontram bem definidos, ou domesticados. Para Ritter e Weber, os wicked problems são mal formulados, não por "incompetência" dos que se debruçam sobre eles, mas porque a quantidade de variáveis que os abraça dificulta que soluções certas ou erradas sejam propostas, uma vez que, segundo os autores, tais soluções, quando apresentadas, não podem ser classificadas de tal forma, mas sim - e no máximo - como "melhores ou piores". Portanto, as condições que envolvem os wicked problems são confusas. Envolvem decisões que atenderão positivamente a certos parâmetros, mas podem impactar negativamente em outros; beneficiará certos usuários, enquanto outros poderão ser prejudicados; além de serem baseadas em propostas que não têm como serem avaliadas com precisão antes de sua própria implantação.

\subsection{Problema de pesquisa}

Neste projeto experimental, foi definido o seguinte problema de pesquisa:

"Como melhorar o conhecimento e a utilização eficiente das linhas de ônibus circulares que atendem a Universidade de São Paulo".

A partir de tal problematização, foram traçados nossos objetivos específicos:

1. Aumentar o conhecimento do usuário sobre os pontos atendidos pelas linhas 8012 e 8022, que circulam dentro da Cidade Universitária, uma vez que nosso público se concentrou nas linhas que acreditamos ser dedicadas principalmente à comunidade acadêmica;

2. Permitir a avaliação, de forma lúdica, dos melhores caminhos para se locomover de ponto a ponto dentro da Cidade Universitária, utilizando daquelas linhas de ônibus ou de deslocamentos a pé.

3. Apresentar a Universidade e os seus principais pontos/localidades de interesse dentro do campus.

\subsection{Utilização de Jogos na aprendizagem}

Para Huizinga (1938), o jogo pode ser visto como "uma preparação do jovem para tarefas mais sérias que, mais tarde, a vida dele exigirá", e "é um elemento anterior a cultura, porém as 
grandes atividades arquetípicas da sociedade humana são desde o início marcadas pelo jogo, e destas atividades podemos destacar a linguagem". Portanto os jogos, desde o início, contemplam em si o caráter didático.

Há também um importante elemento de relações sociais atribuídos ao jogo. Ele é uma forma de entretenimento social com alta capacidade de adaptação. Em sua essência, o lúdico está relacionado à espontaneidade e à despreocupação. (Huizinga, 1938)

Na literatura, há várias referências a jogos, com um viés para a aprendizagem, utilizando diversos termos como: Jogo Educativo, Jogo Didático, Jogo Pedagógico, Objeto de Aprendizagem entre outros. Os filósofos mais antigos já confirmavam o potencial de ensino dos jogos, sendo eles muito influentes no processo de ensino-aprendizagem (CUNHA, 2012). Isso é ressaltado por experiências mais recentes, Batista (2001) diz que "o jogo motiva e por isso é um instrumento muito poderoso na construção de esquemas de raciocínio através de sua ativação". A escolha do jogo como objeto de aprendizagem neste trabalho se mostrou uma solução adequada de Design, tanto pelo seu caráter preparatório e didático, quanto pelo seu caráter social e de alta capacidade de adaptação, tanto pelas suas características duradouras de ativação de raciocínio e engajamento.

\section{Metodologia}

O processo se deu por meio de encontros semanais no período de agosto a dezembro de 2017, com encontros complementares entre os pesquisadores, em vistas do desenvolvimento do jogo, nos quais se planejou as diversas fases do projeto, se desenvolveu os protótipos e se documentou todos os procedimentos.

Uma das abordagens adotada pela equipe foi o Double Diamond (BRITISH DESIGN COUNCIL, 2017), que é a aplicação iterativa de dois processos de pensamento Divergente-Convergente (Brown, 2008). O primeiro deles tem o objetivo de Descobrir e Definir; e o segundo vem para Desenvolver e Entregar (Figura 1).

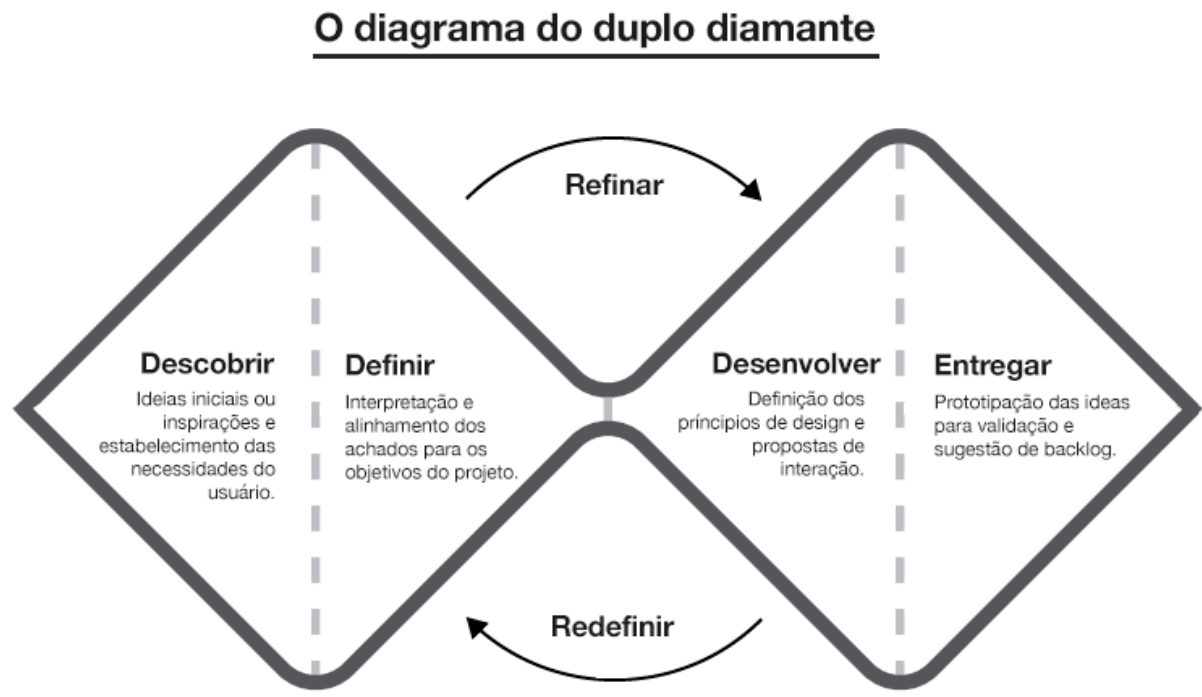

Figura 1: Diagrama do Duplo Diamante. Fonte: Brown (2008)

Na etapa inicial (Descobrir), foi realizada a observação direta do local e de seu contexto; a 
documentação por meio de fotos e vídeos do transporte público na Cidade Universitária; a avaliação dos mapas locais (disponibilizados online pela Prefeitura do Campus); e utilização do sistema de localização Google Maps.

O problema abordado foi definido de maneira pessoal e direta, no que diz respeito ao contato com a situação em estudo. De acordo com Lüdke e André (1986, p. 26) "a experiência direta é sem dúvida o melhor teste de verificação da ocorrência de um determinado fenômeno. A observação direta permite também que o observador chegue mais perto da 'perspectiva dos sujeitos', um importante alvo nas abordagens qualitativas".

O processo experimental culminou no ciclo de pensamento convergente, que resultou na definição do problema de pesquisa: como melhorar o conhecimento e a utilização eficiente das linhas de ônibus circulares que atendem a Universidade de São Paulo.

A partir de então, se deu início à terceira etapa do processo, a de desenvolvimento. Os esforços da pesquisa voltaram-se à tarefa de articular questões levantadas à jogabilidade do produto em desenvolvimento, de forma que as experiências coletadas durante as fases de Descobertas e Definições fossem contempladas nas regras e conteúdo do jogo, desde a marca/nome, passando por cartas, tabuleiro etc.

Este processo iterativo de formulação de aspectos do problema, a construção de protótipos, o teste de diversas versões do jogo, culminou no processo convergente conhecido como 'etapa 4' do Diamante Duplo chamado de Entrega, que corresponde a versão final do jogo.

\subsection{As Etapas de Desenvolvimento}

A formulação do problema partiu da investigação sobre mobilidade dentro da Cidade Universitária, uma vez que todos os membros da equipe já haviam passado por experiências confusas em relação à temática, bem como conheciam histórias semelhantes a partir de relatos de terceiros.

Durante um dos processos em campo, ao mapear a sinalização na região dos bancos (na USP), um dos pesquisadores foi abordado duas vezes por pessoas pedindo informações a respeito de como chegar a destinos específicos. O primeiro, em um carro, que gostaria de chegar à "praça dos bancos", estava há 500 metros desta, porém a sinalização mal distribuída não o ajudava. O segundo, também de carro, iria encontrar um professor na "Biblioteca Brasiliana", à qual já havia passado em frente sem tê-la visto.

Outro procedimento executado teve como objeto a análise do comportamento do usuário, no caso as pessoas que, de algum modo, tivessem que ir à Cidade Universitária. Foram buscadas informações a respeito de como eram feitas buscas (palavras-chave) ligadas à universidade no sistema de buscas do Google. Os resultados, conforme coletados em 17 de outubro mostram (Figura 2): 


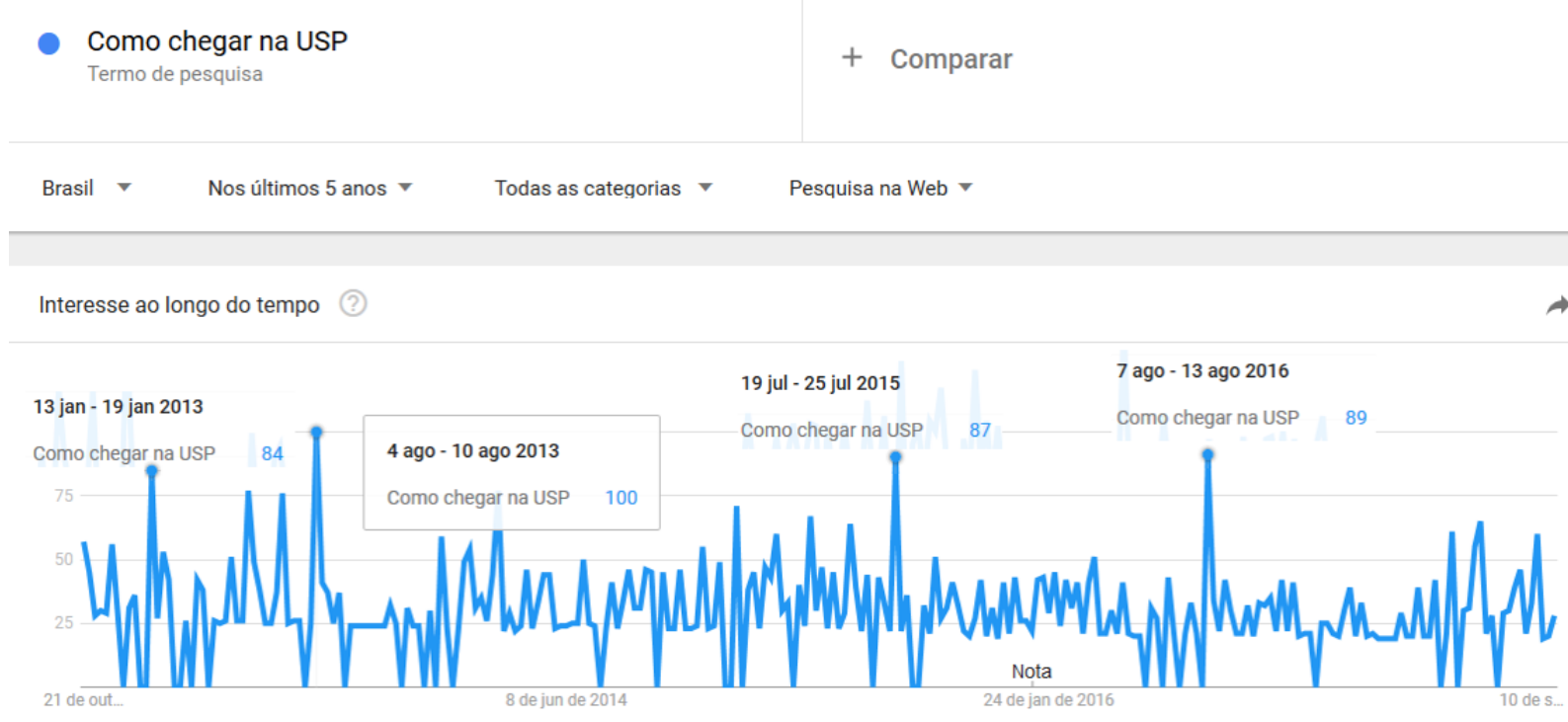

Figura 2: Volume de procura no buscador da Google dos termos “Como chegar na USP"

A discrepância entre o número de pesquisas com o termo USP e com algumas de suas principais unidades reforçou a suposição inicial que tínhamos a respeito de como os usuários buscam localizações na USP. Imaginávamos que um usuário leigo ou que não estivesse envolto à comunidade acadêmica pudesse entender a USP como um lugar em si, ou seja, como um prédio, no qual uma vez nele, se chegasse a qualquer um de seus componentes (cursos, faculdades, unidades etc) por meio de deslocamentos rápidos e precisos.

No decorrer do processo, que fez parte de uma disciplina da Pós-Graduação em Design, os pesquisadores envolvidos neste projeto foram convidados a apresentar ideias e propostas de pesquisa - mesmo ainda sem definição específica de problema. O objetivo era que toda a turma pudesse contribuir. Partindo da grande questão "Mobilidade na USP", estavam entre os aspectos até então considerados a sinalização dentro e fora das Faculdades, Escolas e Institutos; a circulação por automóveis dentro da USP; os espaços para a circulação de bicicletas; e as linhas de ônibus no local. Um tema de interesse convergente foi o da utilização dos ônibus circulares: as linhas 8012 e 8022.

Após a definição de que as linhas citadas seriam nosso objeto de estudo, a pesquisa concentrou-se em coletar experiências relacionadas à utilização do serviço, tanto envolvendo os quatro pesquisadores, quanto outros sujeitos também usuários do transporte.

Com o problema de pesquisa já definido, partimos para o mapeamento da jornada do usuário, que foi feita a partir da gravação de viagem realizada na linha 8012, por um dos pesquisadores. No trajeto, foram identificadas situações relevantes da experiência do usuário:

1. o ponto inicial e de maior movimento dos ônibus circulares: a estação Terminal Butantã, que agrega terminal de ônibus interurbanos e a linha amarela do Metrô de São Paulo. É uma estação de intenso movimento, sobretudo da comunidade acadêmica que frequenta a USP. É a partir deste terminal que saem as linhas circulares 8012 e 8022, que, ao todo, percorrem os 54 pontos de ônibus distribuídos pela Cidade Universitária; 
2. as placas de itinerário dos ônibus somente descrevem as grandes avenidas por onde eles passam, dificultando saber seu real trajeto dentro da universidade, bem como quais os locais atendidos por cada linha;

3. durante a viagem, diversas pessoas questionaram o cobrador a respeito de onde deveriam descer para chegar a seus destinos. A maior parte dos questionamentos veio de indivíduos que pareciam estudantes. Assim sendo, possivelmente de unidades acadêmicas que não as de destino de seus trajetos, uma vez que estávamos já na metade do segundo semestre, quando os calouros já estão bem localizados em relação aos seus centros de estudos. Outros pontos buscados eram bibliotecas e/ou eventos.

A partir da experiência coletada com este modelo de pesquisa, reforçamos duas hipóteses:

1. As pessoas se dirigem à USP, e lá buscam saber seu destino final.

2. Elas buscam informações mais detalhadas perguntando a pessoas, e não por meio de pesquisas prévias em sistemas cartográficos eletrônicos ou em GPS, por exemplo.

Este processo culminou na definição de uma "solução" para o problema de pesquisa que considerasse a melhora de experiência na utilização de ônibus circulares dentro da Cidade Universitária. Dentre as diversas opções que poderiam atender às necessidades almejadas, a utilização do elemento lúdico e a construção de um jogo de tabuleiro foi a que conseguiu agregar a equipe de pesquisadores, uma vez que o jogo poderia ser capaz de cobrir toda uma complexidade de parâmetros relacionados às temáticas de interesse de cada participante.

O desenvolvimento do jogo cobriu três etapas de prototipagem (Figura 3):

1. prototipagem em Papel - Avaliação de funcionalidades mínimas do jogo, unificação do conceito de solução;

2. prototipagem do Jogo Intermediário - Identificação de restrições e problemas não antecipados pela concepção abstrata;

3. prototipagem do Jogo - Teste final de funcionalidades e jogabilidade. 


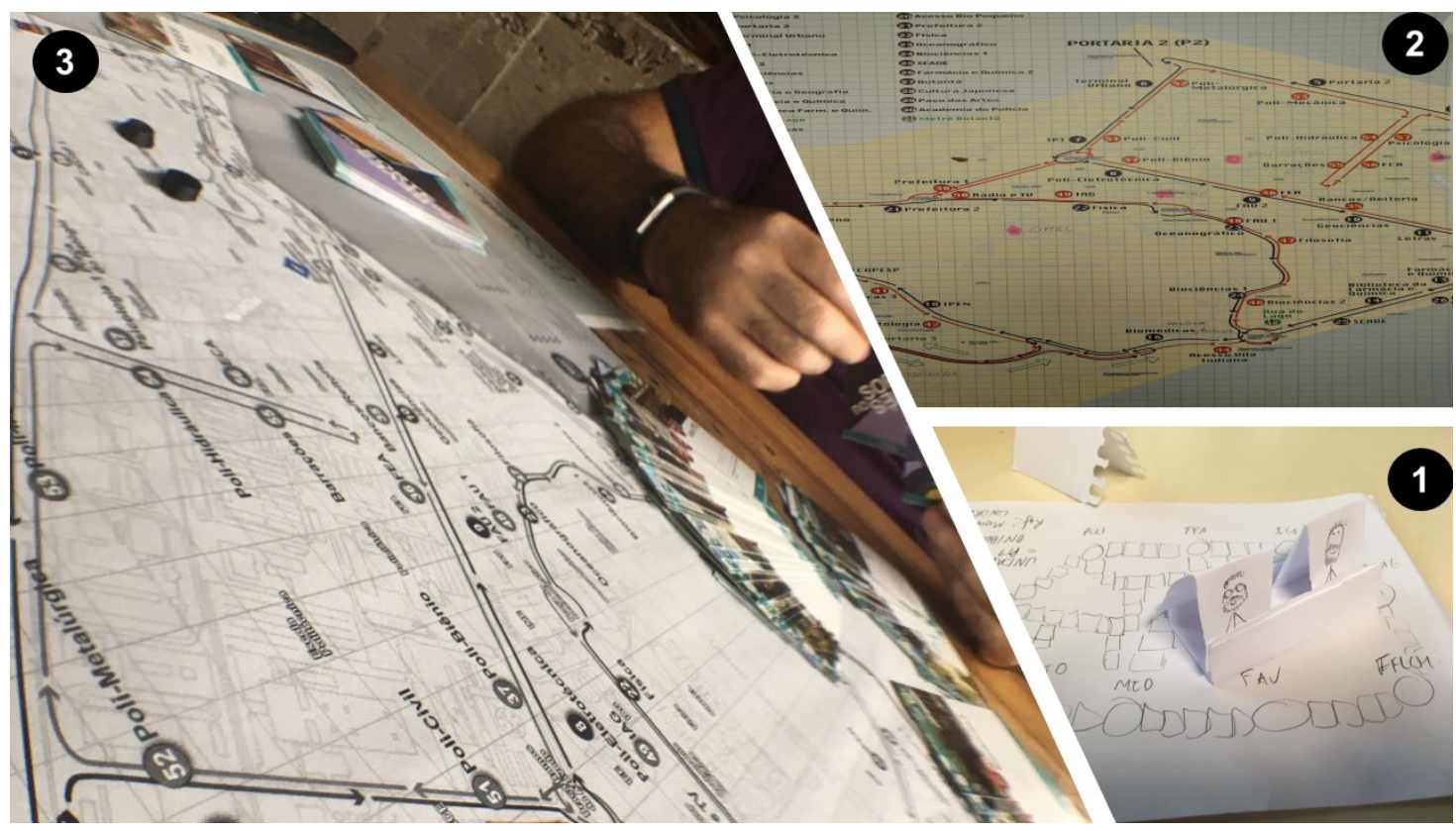

Figura 3: Três etapas de prototipagem diferentes

\subsection{O Design Visual}

O desenvolvimento de toda a configuração visual do jogo USPontos foi realizada na expectativa de envolver o jogador no universo que compõe a sensação visual de estar na Cidade Universitária do campus Butantã da USP. A partir desta referência, foram propostas as diferentes peças e argumentos visuais utilizados, conforme descrito nos subitens a seguir. Antes, contudo, para esclarecimentos metodológicos práticos, informamos que todo o material gráfico foi realizado com o auxílio do software Adobe Illustrator. Entretanto, os rascunhos foram projetados com utilização de lápis e papel.

\section{O nome}

A proposta do nome do jogo USPontos surgiu somente nas etapas finais do projeto. Durante grande parte de seu desenvolvimento, membros da equipe o tratava como "jogo do ônibus". Em nenhum momento, durante a evolução das regras do jogo ou do entendimento de seu funcionamento, a equipe se concentrou em propor uma solução que envolvesse o nome, no entanto, nas fases finais, ou seja, na proposição visual dos componentes de cartas e do tabuleiro surgiu a necessidade de inclusão de marca visual nessas peças, o que foi definitivo para que se propusesse o nome, que, por sua vez, seria a principal instrução na composição do logo.

Não foi utilizado nenhum método formalizado para a proposição do nome. Nem mesmo o clássico brainstorm. Em uma das reuniões formais da equipe, a necessidade de composição de marca foi exposta, e a solução USPontos surgiu. Inicialmente, ela foi encarada com bom humor, mas de imediato foi entendida como uma boa solução, uma vez que se concluiu que a sugestão atendia bem ao objetivo de envolver o jogador na experiência de estar na USP. Tal compreensão surgiu a partir da percepção de que boa parte dos serviços e produtos relacionados à Universidade utilizam da sigla USP como solução, tais como Busp (cartão de ônibus), Crusp (residência estudantil), USPão (padaria anexa ao Crusp), Edusp (editora da universidade), Osusp (orquestra sinfônica), Tusp (teatro), entre outros. 
O jogo tem nas linhas e nos pontos de ônibus seus elementos principais, e como na cidade de São Paulo é comum se utilizar do termo "ponto" para se definir os locais de paradas das linhas de ônibus, a mescla entre "USP" e "Pontos" foi considerado uma boa solução. Para avaliar a percepção de possíveis usuários ao nome, foi feita uma pesquisa informal entre estudantes de diferentes unidades da universidade e também com pessoas externas àquele universo. A leitura "uspontos" foi sempre imediata.

Ao fim do processo, se sentiu a necessidade da proposição de um subtítulo para o jogo, sobretudo para a inclusão deste mote na embalagem. Assim, foi proposto "um passeio na Cidade Universitária" para atender àquela necessidade.

\section{$\underline{\text { A marca }}$}

Solucionado o nome, a próxima etapa foi a proposição da composição visual do logo. $O$ desafio se debruçou sobre a necessidade de fazer com que o leitor do logo a relacionasse com a USP e com pontos de ônibus. Dessa forma, se optou pela utilização do logotipo da universidade, complementada às letras "ontos". Realizado o procedimento, fizemos testes com usuários, que eram questionados sobre o que conseguiam ler na marca proposta. Duas leituras foram explicitadas: USPontos e USP pontos. Imaginamos que a segunda possibilidade seja resultado da identificação do termo USP e da leitura de "Pontos" como estruturas separadas. Desse modo, concluímos que a solução gráfica havia surtido o efeito esperado.

Ao questionar o usuário sobre o que ele entendia daquilo, não recebemos feedbacks suficientes para concluir que a noção de pontos de ônibus foi transmitida. Com essa conclusão, optamos por fazer algumas alterações que pudessem explicitar a sensação do ônibus.

A solução foi descer as letras "o" do baseline da marca e adicionar um contorno semelhante ao desenho do teto dos ônibus que fazem as linhas 8012 e 8022, acima do trecho "ontos". Para reforçar a ideia de movimento, se inclinou em $10^{\circ}$ as letras "o". A proposta foi novamente levada ao crivo de novos indivíduos, mais especificamente um mestrando da Veterinária, um da Poli, um professor da Sociologia (Unifesp) e um doutorando do curso de Farmácia (Universidade Federal do Ceará). Desta vez, ao se questionar sobre a leitura, houve novamente os resultados "USPontos" e "USP pontos"; e ao perguntar sobre a interpretação sugerida, todos afirmaram que a marca se relacionava a ônibus e à USP. As respostas indicaram que as modificações realizadas resultaram na identificação esperada. Contudo, se sentiu a necessidade de explicitar também a circulação à pé no jogo. Tal proposição não foi considerada fundamental mas foi experimentada. Desse modo, a letra " $\mathrm{t}$ " foi substituída pelo desenho de um personagem caminhando. Esta solução pareceu, inicialmente, problematizar a leitura da marca, uma vez que a letra " $t$ " havia sido excluída do desenho. Mais uma vez, então, se testou com novos usuários. A marca foi apresentada a diversas pessoas via Whatsapp, que eram questionadas sobre o que liam e o que entendiam daquilo. Como conclusão, percebemos que a substituição da letra não provocou nenhuma dificuldade na leitura. Da mesma forma "USPontos" e "USP pontos" continuaram como possibilidades e o elemento iconográfico do pedestre foi entendido com um complemento interessante na compreensão da marca, uma vez que alguns entrevistados incluíram nas suas interpretações a ideia de alguém que entra e viaja em um ônibus. 


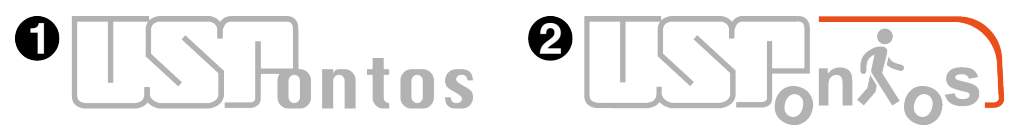

Figura 4: 1. Proposta inicial de marca; 2. Marca final do jogo. Fonte: Autores

\section{A escolha tipográfica}

A escolha tipográfica do jogo se faz presente em todo o conteúdo visual, desde a construção da marca até o manual de uso do jogo. No início do projeto, não houve discussão mais incisiva sobre a tipografia a ser utilizada, mas se sabia que apenas uma deveria ser selecionada, de preferência alguma que contivesse uma família com, pelo menos, três tipos (itálico, negrito e regular). Entretanto, optou-se pela utilização da fonte "Krungthep", que satisfazia critérios de leitura e visibilidade em textos pequenos, mas era esvaziada de sentido e não continha contextualização suficiente para justificar sua presença. É importante ressaltar que os primeiros testes de marca foram realizados com a utilização desta tipografia.

Por fim, o método de desenvolvimento do jogo contou com intenso processo de observação por parte da equipe. Desta observação, se destaca a exploração do sistema de sinalização externa da USP, que conta com cores e tipografia muito características. Uma vez que traçamos como objetivo envolver o jogador no universo visual da Universidade, resolvemos identificar a tipografia utilizada nos totens identificadores que povoam o campus da Cidade Universitária, verificar sua disponibilidade de uso gratuito e avaliar sua utilização nas diversas peças que compõem o jogo. Dessa

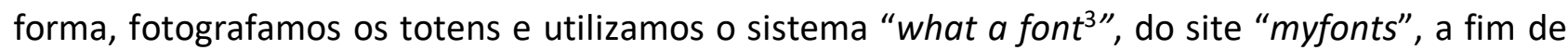
fazer a identificação. O procedimento revelou que a fonte utilizada seria a "Arial", em formatos regular, negrito e itálico. Tal tipografia atendia a todas as necessidades do projeto e, portanto, foi selecionada e utilizada.

\section{As cores}

Assim como a definição da tipografia Arial, baseada na observação dos totens de sinalização da USP, as cores tomaram tais recursos como referência, bem como as cores das linhas 8012 e 8022 . A cor laranja é presente nos dois ônibus, e por isso não seria suficiente para identificar as duas linhas, uma vez que considerávamos fundamental a utilização de contraste cromático entre elas. Dos processos de observação, foi identificado, no interior dos ônibus, o padrão que ilustra o tecido dos assentos das duas linhas, que apresenta uma mistura entre tons de azul (mais claro e mais escuro) e amarelo. Tal padrão foi adotado como referência para preencher o verso de todas as cartas Origem/Destino, bem como sua cor mais escura orientou o contraste com o matiz laranja. Da mesma forma, os tons de azul em questão serviram de verso para as cartas Sorte/Revés. As cores laranja e azul escuro foram definidas para identificar os trajetos e os pontos das duas linhas de ônibus - uma para cada.

\section{As cartas}

As cartas fundamentais do jogo se referem a todos os 54 pontos de ônibus atendidos pelas

\footnotetext{
3 Sistema online capaz de identificar a fonte de uma imagem em pixel.
} 
linhas 8012 e 8022 dentro da Cidade Universitária e o ponto do Terminal Butantã, haja vista o fluxo de pessoas que desembarcam neste terminal para seguir viagem nos circulares. Além das cartas de pontos, definimos identificar, também, unidades que se encontram dentro do campus mas que não correspondem exatamente a um ponto de ônibus, tal como o CEPEUSP e os bandejões, que atendem a um grande número de pessoas mas não são localizados por pontos de ônibus.

Originalmente, o jogo se baseava na proposta de se deslocar à pé ou nas linhas 8012 e 8022 dentro do Cidade Universitária, contudo, durante os encontros para delimitação de regras e fluxo do jogo, se definiu a inclusão das cartas Sorte/Revés, com o objetivo de tornar o jogo mais dinâmico e divertido.

A construção das cartas Origem/Destino se dá pelo uso de imagem fotográfica que representa o ponto, somado à informação sobre a linha que o atende. Nestas cartas também são identificados, para fins didáticos, os pontos anterior e seguinte, seu endereço, o detalhamento do nome do ponto (caso trate de uma sigla como FAU, por exemplo) e as unidades e pontos que ficam nas proximidades.
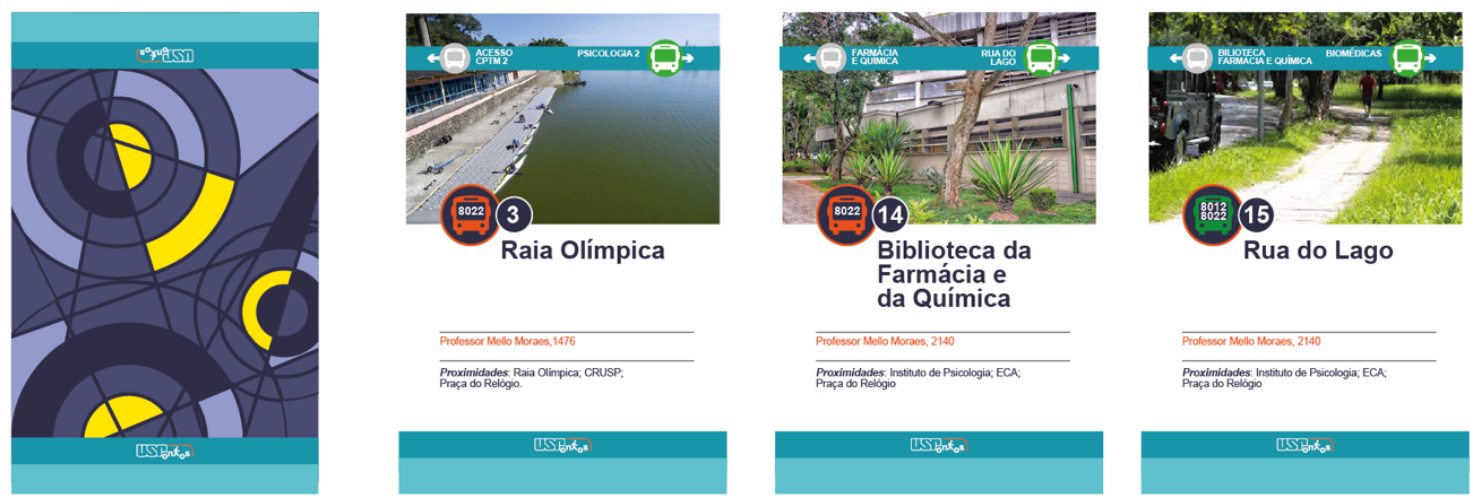

Figura 5: Exemplos de cartas Origem/Destino. À esquerda, o verso deste conjunto. Fonte: Autores

Para a construção das cartas Sorte/Revés, foi utilizada a mesma configuração formal das cartas anteriores, entretanto, as informações são diferentes. Nelas, são encontradas situações comuns àqueles que frequentam o campus à pé ou de ônibus, ilustradas por memes ${ }^{4}$, e finalizadas por orientação que define a atitude que o jogador deve seguir na rodada em que puxa tal carta.

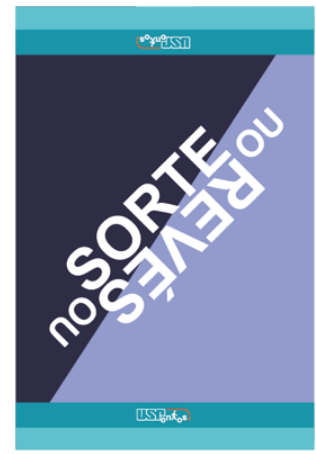

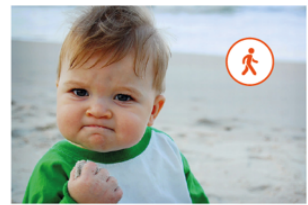

SORTE!

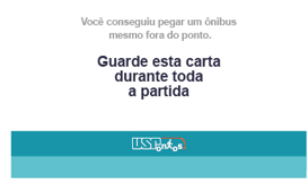

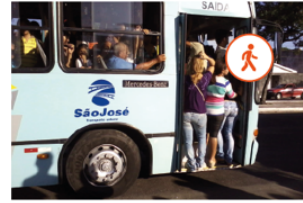

REVÉS!

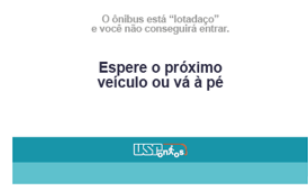

Figura 6: Exemplos de cartas Sorte/Revés. À esquerda, o verso deste conjunto. Fonte: Autores

\footnotetext{
${ }^{4}$ De acordo com Dawkins (2007), memes são unidades de transmissões culturais. Neste caso, são imagens que devido sua massificação de uso e de entendimento, passaram a ter status quase que ideológico ou verbal. Os memes, neste trabalho, são todos ligados ao universo ocidental e com conteúdo risível.
} 
A seleção fotográfica que ilustra as cartas Origem/Destino foi realizada com utilização dos recursos Google Imagens e Google Street View. Inicialmente, se cogitou a possibilidade de os próprios pesquisadores da equipe realizarem o trabalho fotográfico. Entretanto, não houve disponibilidade de tempo para realização satisfatória desta tarefa, e uma vez que foram encontradas boas imagens livres e gratuitas na web e que não eram necessárias fotografias em alta resolução, se optou pela solução mais prática.

No caso das cartas Sorte/Revés, a equipe decidiu utilizar memes popularizados na internet, pois houve o entendimento de trazer humor e mais diversão aos jogadores. Da mesma forma, se compreendeu que tal artifício poderia cativar e interessar mesmo aqueles indivíduos que nunca estiveram na Cidade Universitária, uma vez que os memes podem ser entendidos como bons recursos de empatia com o público.

\section{O tabuleiro e as peças}

A construção do tabuleiro foi o item mais complexo de se solucionar. Primeiro porque teve que abranger uma enorme quantidade de informações (pontos, fluxos, institutos, ruas, etc), o que significou um estudo detalhado sobre o quê e como incluir tal conteúdo, bem como identificar as possibilidades de impressão. Além disso, foi necessária uma avaliação detalhada sobre como identificar visualmente os diferentes percursos a serem percorridos por jogadores à pé ou de ônibus, uma vez que tal definição é fundamental para a jogabilidade.

A fim de encontrar soluções eficientes, pesquisamos diferentes jogos de tabuleiro oferecidos no mercado. Dentre eles, nos baseamos nos famosos "Interpol", "Ludo", "Batalha Naval" e "Banco Imobiliário", que além de contribuir com a solução visual do tabuleiro, foram ótimas referências para a proposição das regras. Do Interpol, por exemplo, nos baseamos na utilização de um mapa como referência informacional; e do "Batalha Naval", se utilizou dos módulos que representam os caminhos que podem/devem ser seguidos pelos jogadores à pé.

Por fim, o estabelecimento do formato total do tabuleiro (A2) definiu o tamanho das células/módulos/casas/pontos à pé, o que, por consequência, foi decisivo na proposição do tamanho das peças dos jogadores e dos ônibus ${ }^{5}$.

\section{As regras}

O conjunto de regras do jogo foi fruto de longo período de amadurecimento da proposta da equipe. Partiu-se da ideia de que o objetivo do jogador seria o de percorrer determinado espaço entre ponto de origem e de destino, se utilizando das linhas 8012,8022 ou à pé. A partir de então, tomou-se como referência uma série de jogos clássicos de tabuleiro - como já citados anteriormente.

É importante destacar que um dos processos que mais ajudaram na proposição das regras foram as cartas Sorte/Revés, que nos fez refletir sobre as possibilidades que o jogo poderia oferecer, a ponto de que as regras apresentadas são, no geral, sugeridas e não obrigatórias, o que confere ao

\footnotetext{
5 As peças de jogadores são quadradas e $80 \%$ da área ocupada por um módulo; as de ônibus são ligeiramente mais largas que uma peça de jogador e $30 \%$ mais comprida que a soma de duas destas peças.
} 
jogo um caráter experimental e único para cada situação e conjunto de pessoas que o façam uso.

\section{Produção Gráfica}

Como já citado, se utilizou do software Adobe Illustrator para desenho de todo o conteúdo visual do jogo. Ao todo, os arquivos utilizados para desenvolvimento do USPontos ocupam mais de 1,5GB de espaço no HD, entre arquivos de testes, finais, imagens fotográficas e referencial. Todo o material (cartas Sorte/Revés, peças, cartas Origens/Destino) foi impresso em cores (CMYK), impressão a laser, em papel couche $300 \mathrm{~g}$, com acabamento por meio de corte com guilhotina em sangria de $5 \mathrm{~mm}$. O tabuleiro, por sua vez, foi impresso em duas partes (duas folhas de formato super A3), colorido em CMYK e com acabamento empastamento em percalux, e laminação fosca, posteriormente dividida em quatro partes de formato A4. A caixa, de tamanho $30 \times 30 \times 8 \mathrm{~cm}$, não foi feita pelos membros da equipe, mas adquirida em loja especializada em material MDF, coberta com tinta látex na cor branca e adesivada com a identidade visual do jogo. Atualmente, todo o conteúdo do jogo, inclusive seu manual de regras, está disponível para download gratuito no site pessoal de um dos autores $^{6}$, sob o título USPontos.

\section{Resultados}

Como já mencionado, o desenvolvimento do jogo não teve como fim a solução de um problema, até pela natureza apontada, um wicked problem (RITTEL; WEBBER, 1973), tal meta foi desconsiderada. Entretanto, a partir dos objetivos elencados no "problema de pesquisa" (ver página 3), podemos considerar que o jogo atendeu às necessidades, uma vez que aqueles que tiveram acesso ao mesmo foram capazes de entender a sistemática do jogo, suas regras, contexto e cartas, se identificaram com as situações descritas nas cartas; reconheceram trajetos que fazem em suas vidas cotidianas; perceberam espaços que Ihe eram ainda desconhecidos; e tiveram clarificados os percursos realizados pelas linhas 8012 e 8022 .

Vale ressaltar, entretanto, que não houve sistematização para julgar, detalhadamente os resultados descritos acima, uma vez que o experimento se restringiu à turma à qual foi ministrada a disciplina que incentivou a criação do jogo e deste trabalho. Contudo, consideramos que a aula de apresentação e avaliação dos trabalhos finais foi suficiente para perceber a imersão e identificação daquele público no contexto do jogo, já que a intensa participação da turma, que jogava, filmava, fotografava, fazia postagens em redes sociais, se divertia e comentava as várias situações apresentadas nos diversos dispositivos visuais do jogo deixou transparecer características elencadas por Kishimoto (1994), quando aponta que o jogo educativo desperta funções lúdicas e educativas, que coexistem em equilíbrio; ao que Piaget (1973) poderia complementar sugerindo que o aprendizado, neste momento, é apoiado pelo procedimento, uma vez que da interação entre sujeito (jogador) e objeto (jogo) é que são construídas e desconstruídas as estruturas cognitivas.

Julgamos, por fim, que para qualificar a real eficácia do jogo USPontos como recurso educativo, seria necessário nos valermos de dispositivos de avaliação da área da Pedagogia e Cognição, o que, neste caso, extrapola as intenções dos autores deste trabalho.

\footnotetext{
${ }^{6}$ www.dn.ppg.br
} 


\section{Considerações Finais}

Este artigo buscou descrever de forma didática os processos que envolveram o desenvolvimento do jogo "USPontos: um passeio na Cidade Universitária", e mesmo que tenha sido originado a partir da identificação de um complexo problema de localização, sinalização, identificação e compreensão dos pontos de ônibus e da circulação à pé na sede da USP no Butantã, não se objetivou a solução de tais questões, uma vez que se considerou necessário um alto nível de envolvimento e soluções projetuais que ultrapassariam os objetivos da disciplina "Design Visual: processos experimentais", bem como as condições de tempo e trabalho da equipe envolvida. Além de que a Universidade dispõe de setores e profissionais com propriedade suficiente para propor tais soluções. Supõe-se que a execução de projetos de tal magnitude esbarre em questões orçamentárias, haja vista o volume de investimento que poderia demandar.

Contudo, a exploração do problema a partir de viés lúdico, com proposição de um jogo de tabuleiro capaz de envolver tanto comunidade universitária quanto público externo que frequenta (ou não) aquele ambiente se demonstrou como um excelente processo de experimentação de diversos componentes que envolvem a produção em Design Visual, desde a criação de uma marca, à composição de identidade visual, definida por cores, tipografia, proporções, elementos iconográficos entre outros, tanto quanto pela proposição de regras e orientações que permitam aos usuários um conhecimento básico sobre o que pode encontrar no campus da Cidade Universitária da USP. Compreendemos que o jogo USPontos serve tanto de orientação para aqueles que já contam com alguma relação com o campus quanto como com aqueles que nunca estiveram naquele lugar. 


\section{Referências}

BATISTA, G.O. A importância dos jogos lógicos nas séries iniciais do ensino fundamental. Rio de Janeiro: Universidade Candido Mendes, 2001.

BIRNEROVÁ, E. Assessment of Customer Satisfaction in Public Transport Companies. Promet - Traffic\&Transportation, v.19, n.3, p.163-166, 2007.

BREDA, T. V. O Uso de Jogos no Processo de Ensino Aprendizagem na Geografia Escolar. Campinas: Unicamp, 2013.

BRITISH DESIGN COUNCIL. Eleven lessons. A study of the design process - www.designcouncil.org.uk. Acessado em 4 Dezembro de 2017.

BROWN, T. Design Thinking. United States:Harvard Business Review, 2008.

BUCHANAN, R. Wicked problems in design thinking. Design Issues, V. 8, 1992

CASTELLAR, S.V.; MORAES, J. V. Ensino de Geografia Coleção Ideias Em Ação. São Paulo: Cengage Learning, 2010.

CUNHA, M.B. (2012) Jogos no ensino de Química: Considerações teóricas para sua utilização em sala de aula. Química nova na escola, 34(2), p. 92-98.

DAWKINS, Richard. 0 gene egoísta. São Paulo: Companhia das Letras, 2007.

HUIZINGA, J. Homo Ludens: O Jogo como Elemento na Cultura (1938). São Paulo: Perspectiva, 2008.

Kishimoto, T. M. 1994. O jogo e a educação infantil. São Paulo: Pioneira.

LIEDTKA, J; OGILVIE, T. A magia do Design Thinking - Um kit de ferramentas para o crescimento rápido da sua empresa - HSM do Brasil, 2015

LÜDKE, M.;ANDRÉ, M. D. A. Pesquisa em educação: abordagens qualitativas. São Paulo, EPU, 1986.

NOBLE, I.; BESTLEY, R. Pesquisa visual: introdução às metodologias de pesquisa em design gráfico.

2. ed. Porto Alegre: Bookman, 2013.

PIAGET, J. 1973. Estudos sociológicos. Rio de Janeiro: Forense.

RITTEL, H.; WEBBER, M. Dilemmans in general theory of planning. Policy Sciences, v. 4, 1973

RODRIGUES, J. S. Gestão do Transporte Público do Município de São Paulo: Implementação da política nacional de mobilidade urbana, 2014

USP. Prefeitura do Campus da Capital. Cuaso em números: dados gerais 2017. Disponível em: <http://www.puspc.usp.br/wp-content/uploads/sites/159/2017/07/Dados-Gerais-do-Campus-

2017.xlsx-Plan1-1.pdf>. Acesso em: 26 mar. 2018.

\section{Manuais:}

INSTITUTE OF DESIGN AT STANFORD UNIVERSITY, Bootcamp Bootleg D.School V3, BOTH, T.; BAGGEREOR, D. United States: d.school, 2010.

https://dschool.stanford.edu/s/METHODCARDS-v3-slim.pdf acessado em Out/2017. 